\title{
BAILE COMO EXPRESIÓN DE FEMINEIDAD Y EROTISMO EN FEDERICO GARCÍA LORCA ${ }^{1}$
}

\author{
Miriam Yvonn Márquez Barragán²
}

\begin{abstract}
Baile como expresión de femineidad y erotismo en Federico García Lorca
Resumen: El baile a lo largo del tiempo ha sido visto como una actividad peligrosa para los valores morales y religiosos. El cuerpo de la mujer ha sido visto como un medio para excitar el pecado. La obra dramática de Federico García Lorca logra capturar el conflicto moral y las implicaciones sexuales del baile con personajes femeninos que luchan entre el deseo y sus instintos. En el presente trabajo, analizo algunos de los valores sociales y morales del baile en el teatro de Lorca.

Palabras clave: Federico García Lorca, Danza, transgresión, cuerpo, estigma social.
\end{abstract}

Abstract: Over time, dance has been perceived as an activity threatening certain moral and religious values. The female body is the expressive instrument in dancing, as a mean to incite sinful behavior. The dramatic work of Federico García Lorca capture the moral conflict and the sexual implications of the dance with female characters who struggle between desire and their instincts. In the present article, I review some of the negative social and moral values present in dancing, in Lorca's view.

Key words: Federico Garcia-Lorca, dance, transgression, body, social stigma.

\section{Introducción}

El baile como hecho social tiene múltiples y complejas significaciones que a lo largo de la historia han ido cambiando, en una continua tensión entre los valores morales y religiosos de cada cultura y las pulsiones sexuales que el ser humano arraiga en su propia naturaleza. En occidente, durante la Edad Media, se consideró a la danza como una actividad inapropiada, frívola, y peligrosa para la castidad, especialmente para las mujeres. La Iglesia

\footnotetext{
${ }^{1}$ Fecha de recepción: 17/04/2018.

Fecha de aceptación: 29/11/2018.

${ }^{2}$ Candidata a Doctora en Romance and Arabic Languages and Literatures, University of Cincinnati, Estados Unidos; $₫$ marquemn@mail.uc.edu.
} 
se convirtió en el mayor enemigo de la danza, causa de pecado venial, incluso mortal, como se expresa en Summa Astensis, por considerar que bailar era una gran ofensa a los Sacramentos (Wagner 1997: 3). Sin embargo, estos valores comenzaron a cambiar con el Renacimiento, época en que aparecieron los primero maestros, coreógrafos y bailarines profesionales, así como también los primeros manuales de danza. Debido a que la instrucción de este arte costaba dinero, la danza se consideró una actividad de la nobleza, benéfica para resaltar los valores de belleza y elegancia, siempre y cuando los movimientos fueran discretos: "Dancing was blended with manners and proper behavior, and it was generally believed that orderly movement was moral and disorderly movement was not" (Knowles 2009: 4). No obstante, a pesar de esta clara distinción y prejuicio, que ha permanecido parcialmente hasta nuestros días -en cuanto a la cualidad de los movimientos y bailes considerados morales e inmorales (en especial los que son practicados en un ambiente popular)-, la actividad dancística fue vista hasta alrededor de $1960^{3}$ como un pasatiempo físicamente riesgoso, espiritualmente lascivo, y económicamente absurdo y frívolo por instituciones religiosas, como la iglesia católica y protestante, sin importar la clase social en donde se practique. Si bien la percepción de las danzas populares y folclóricas representadas en las plazas públicas son diametralmente opuestos al significado que tuvieron los bailes de salón para aristócratas y burgueses, ambos ambientes eran vistos bajo una óptica negativa dentro de los preceptos de moralidad, una actividad poco cristiana, puesto que se hacían con motivos festivos, a veces con alcohol de por medio, donde se relajaban las conductas, el

\footnotetext{
${ }^{3}$ Señala Ann Wagner que en Estados Unidos, a partir de 1840, comenzó una popularización de los bailes. La aparición y masificación del cine y la televisión en el siglo XX tuvieron un impacto mayúsculo en la gente que veía sin mayor recelo dicha actividad. No así las instituciones religiosas, que han considerado la danza como un instrumento de relajación moral para los jóvenes, vinculado a ambientes viciosos y movimientos pecaminosos.
} 
momento ideal para muchos de romper con las rígidas ataduras sociales, una manera de liberarse. Incluso los espectáculos dancísticos que comenzaron a crecer en popularidad en los círculos más cosmopolitas en los inicios del siglo XX fueron vistos como un derroche de tiempo y dinero, de naturaleza sensual e impropia por la sugerencia del cuerpo o bien, por la desnudez parcial. No obstante, la danza clásica, ha buscado un deslinde entre el baile como divertimento y como profesionalización, esmerándose en poner el acento en el baile como un arte del cuerpo, eliminando las connotaciones negativas y realizando las cualidades espirituales del cuerpo, contrarrestando así las emociones sexuales y estableciendo casi una filosofía del profesional de la danza:

Dancers infrequently experience their art as sexual: even when their limbs are wrapped around each other or they are joined an impassioned embrace, ballet is too unreal and contrived -pure artifice- and requires too much work and technical concentration to permit arousal. If anything, ballet is purifying, every moment physically honed and essential, with no superfluity or excess: it is a kind of grace. But if ballet is not inherently sexual, it is often highly sensual and erotic: the human body publicity revealed. If there is a tension here between physicality and spirt, earth and heaven. It is resolved: even at its most risqué, ballet remains an idealized art. (Homans 2010: XXII-XXIII)

Por el contrario, otros tipos de danzas urbanas son vistas como una provocación a los sistemas sociales más conservadores. La revelación del cuerpo en movimiento era visto en los albores del siglo pasado como una transgresión, una forma de resistencia contracultural. El flamenco, el tango, el charleston, el cakewalk, entre otros bailes, físicamente sensuales y que muestran otra forma de la feminidad. Estos bailes tienen una naturaleza subversiva, el cuerpo se vuelve un instrumento de resistencia ideológica para los grupos más desfavorecidos, por lo que se vuelven significativos racial y socialmente. Estos bailes populares, se alejan de manera radical de la figura de la ballerina clásica decimonónica, que 
se define como la figura etérea y frágil, el ideal del romanticismo, la mujer delicada, de delgadez y palidez extremas, siempre en la búsqueda del desprendimiento del suelo a través de una compleja variedad de saltos y especialmente, por los delicados instrumentos de tortura que solían ser las zapatillas de punta ${ }^{4}$ y los apretados corsés para hacerla ver más espigada. ${ }^{5}$ Por el contrario, la feminidad de la bailarina de danzas populares y urbanas busca tener un contacto más terreno, los pies siempre en contacto o bien golpeando con firmeza el suelo, el cuerpo libre mostrando sus verdaderas formas, ejerciendo una danza telúrica, "pagana", voluptuosa, pero ante todo, mostrar el placer del baile desplegado en una inagotable inventiva del movimiento corporal. Esta característica es quizá la que comenzó a hacer este tipo de bailes atractivos para los públicos teatrales de 1910 y en adelante, que comenzaron a “estilizar” y a articular más profesionalmente la fusión entre las danzas populares sumándolo al vocabulario de la danza clásica. Por ejemplo, señala Mark Knowles que durante finales del XIX y las primeras décadas del XX los bailes de salón cobraron enorme popularidad y voracidad del público por verlos, por lo que se convirtieron en una gran oportunidad para los empresarios teatrales para enriquecer sus espectáculos incluso si estos números tenían poco o nada que ver con la trama principal: "Dance teams used popular dances of the period and

\footnotetext{
${ }^{4}$ En el documental Bailarina en cuerpo y alma (Ballerina. Body and soul) que narra la primera ballerina Natalia Makarova, se describen a las primeras zapatillas de punta usadas a finales del siglo XIX y principios del XX como de hormas estrechas para comprimir el pie "de modo que toda la energía salía de los huesos que quedaban en forma de tubo." Sin embargo, desde mediados del siglo pasado comenzó una "rebelión" de las bailarinas porque las zapatillas de punta fueran menos dolorosas. Algunos sistemas, como el cubano, hasta hace unos años no admitían el uso de almohadillas o algodones para evitar el sangrado del pie.

${ }^{5}$ En Letters on Dancing and Ballets, Jean Georges Noverre describe los pesados trajes y apretados corsés que los bailarines deben llevar, por lo que hace un claro reclamo a esta forma de aprisionamiento del cuerpo y su capacidad expresiva. Durante las vanguardias, algunos diseñadores como Oskar Schlemmer privilegiaron la forma por la movilidad del cuerpo. Sus diseños eran conocidos por su complejo entramado de formas, pero difíciles de llevar en escena. Los diseñadores alemanes Lavinia Schulz y su pareja Walter Holdt también crearon una serie de diseños de enorme creatividad vanguardista, pero que llegaban a ser dolorosos. En este sentido, la danza escénica y el dolor han tenido una relación misteriosa con el dolor. Agradezco a la doctora Michelle Clayton, profesora en Brown University, la referencia de estos diseñadores.
} 
stylized them in a theatrical way to appeal to their audiences, thus modifying and refining them" (Knowles 2009: 73). Esta situación es compartida por el flamenco, el tango, el charlestón, y demás bailes que "se dignificaron", es decir, que fueron "saneados" del componente excesivamente sexual para que los grandes públicos pudieran apreciarlos sin correr el riesgo de la censura pública.

En 1909, Sergei Diaghilev crea los Ballets Russes, la primera compañía de danza que moderniza la manera de presentar espectacularmente esta disciplina. Con una formación de músico, pintor y productor de ópera, Diaghilev supo combinar y proyectar el talento de una gran variedad de artistas e intelectuales como empresario y director artístico poniendo el trabajo de cada uno en igualdad de importancia. A su lado colaboraron las mejores mentes de su época como las luminarias de la danza Vaslav Nijinsky, Tamara Karsavina, Anna Pavlova, los coreógrafos Michael Fokine, Leónide Massine, Bronislava Nijinska, George Balanchine, los directores de escena Konstantin Stanislavsky y Vsevolod Meyerhold, los compositotres Igor Stravinsky, Maurice Ravel, Erik Satie, Manuel de Falla, los pintores Pablo Picasso, Juan Griss, Joan Miró, Henri Matisse, los escriores y libretistas Jean Cocteau, María Lejárraga, Gregorio Martínez Sierra, la diseñadora Coco Chanel, por mencionar algunos de la larga lista de colaboradores (Murga 2009: 16).

\section{EI baile en la obra de García Lorca}

A través de Manuel de Falla y Gregorio Martínez Sierra, Federico García Lorca comienza su fructífera carrera en el teatro vinculando la vanguardia (en una nueva forma de 
hacer teatro combinando elementos de diferentes disciplinas) y tradición (al rescatar temáticas y ambientes populares en su teatro. Es interesante notar cómo Lorca participa en el proceso de estilización de la danza en su teatralización, pues podemos encontrar elementos dancísticos en las obras lorquianas, como la danza ritual del macho cabrío en Yerma, o el cuadro de la boda en Bodas de sangre, pero deja latentes las resonancias sociales y morales en algunas de sus obras, nítidos ejemplos de contrastantes feminidades a través de alusiones al baile, que se convierte en un mensaje de múltiples significados. Esto lo observamos en la primera escena de Mariana Pineda, cuando llegan de visita LuCíA y AMPARO a casa de la protagonista. En la escena II se ve el contraste de las tres mujeres, especialmente entre las dos hermanas: "Lucía es rubia tostada, y Amparo, morenísima, de ojos profundos y movimientos rápidos." A través de los diálogos vemos que AMPARO destaca por su simpatía y desenvoltura:

\author{
AMPARO: Mientras \\ que mi hermana lee y relee \\ novelas y más novelas, \\ o borda en el cañamazo, \\ rosas, pájaros y letras, \\ yo canto y bailo el jaleo \\ de Jerez con castañuelas: \\ el vito, el ole, el sorongo, \\ y ojalá siempre tuviera \\ ganas de cantar, señora. (Lorca 1971: 786) ${ }^{6}$
}

Así, apreciamos cómo las dos hermanas en sus diferencias de conducta, Lucía rubia, más recatada y AMPARO morena y actitud más abierta y alegre. Ella contrastará más abiertamente con MARIANA, que se muestra desde su aparición en la escena, inquieta y

\footnotetext{
${ }^{6}$ Todas las citas de las obras de Federico García Lorca proceden de esta edición.
} 
afligida. También crucial diferencia entre los temas que distinguen a las dos mujeres, pues mientras MARIANA se ocupa del bordado una bandera independentista y está preocupada por su amante, AMPARO tiene otras cosas en la cabeza:

AMPARO: No me has preguntado por mi estancia en Ronda.

MARIANA: Es verdad que fuiste; ¿y has vuelto contenta?

AMPARO: Mucho. Todo el día baila que baila. (791)

AMPARO describe con gran detalle la corrida de toros en Ronda, misma que contagia a MARIANA de alegría por un instante. Vemos que la coquetería de AMPARO, es reprendida en varias ocasiones por su hermana LUCÍA, mientras que MARIANA es más indulgente e incluso disfruta, en su inquietud, de lo que le dice su amiga, como cuando le dice “¡Cuéntame! Si vieras/ cómo necesito de tu risa fresca risa, / cómo necesito de tu gracia joven” (792), por lo que asumimos que la puerilidad de AMPARO no es un defecto a los ojos de MARIANA, sino que es casi una virtud de alegría y juventud.

Diferente es la forma en cómo el baile, el canto y la coquetería son vistos en La zapatera prodigiosa. Por ejemplo, el baile de la ZAPATERA es un momento íntimo, donde ella fantasea con bailar con diferentes hombres; sin embargo, estas ensoñaciones contrastan con la forma en que la ZAPATERA actúa en relación al ALCALDE, Don MiRLO, y los Mozos que la cortejan. Ella establece una tajante línea entre la coquetería de su personalidad con su trato con los hombres del pueblo, aunque son las mujeres de su entorno las que la miran con desconfianza y desaprobación. En este sentido, AMPARO y la ZAPATERA se parecen como personajes alegres que expresan de una manera u otra su gusto por bailar, y por ello, se salen de la norma establecida. 
Otro ejemplo de esta alusión social al baile la encontramos en Doña Rosita la soltera, donde la TÍA y el AmA hablan sobre las flores del jardín llena de raras y variadas flores que, sin embargo, no le gustan a el AMA por considerarlas que "huelen a niño muerto, o a profesión de monja, o a altar de iglesia. A cosas tristes" (1352). Para el AMA prefiere árboles frutales en un claro contraste, pues las flores representación la pureza y belleza "efímera" contra la fertilidad y permanencia de los árboles frutales, que puede ser interpretado en un sentido alegórico de la castidad de la mujer y su rol pasivo, contrario a la fertilidad y el rol activo. En este sentido, el AMA se muestra más abierta a los deseos femeninos, como la comida, el baile y el sexo ${ }^{7}$ :

AMA: [...] ¡Qué ganas tengo de ver plantados en este jardín un peral, un cerezo, un caqui! TÍA: ¡Para comértelos!

AMA: Como quien tiene boca... Como decían en mi pueblo:

La boca sirve para comer, las piernas sirven para la danza,

y hay una cosa de la mujer...

(Se detiene y se acerca a la Tía y lo dice bajo)

Tía ¡Jesús! (Signando.) (1353)

El elector intuye que lo dice el AMA tiene una connotación juguetonamente sexual que escandaliza a la TíA. Más adelante, en el segundo acto, vemos el baile de RositA con sus amigas las AYOLA y las SOLTERAS, más propio para una señorita de sociedad como lo son ellas, un baile recatado y totalmente despojado de sensualidad. Es destacable el factor de la

\footnotetext{
${ }^{7}$ La comida, el baile y el deseo sexual tienen una larga e histórica convivencia negativa con los valores de las clases elevadas, y con la figura de la mujer "recta" y "casta." El recurrir a dietas aberrantes que mantuvieran delgada a una dama de sociedad era totalmente aceptado. La delgadez estaba vinculada al ideal romántico, la idea de una mujer frágil y de temperamento melancólico, asexuada eran valores relacionados con la nobleza y elegancia.
} 
ausencia de hombres jóvenes que sirvan de acompañantes, por lo que este baile está completamente inmunizado de erotismo.

Por otro lado, el baile, como marcador de los prejuicios morales, raciales y de clase también se hace evidente en La casa de Bernarda Alba, donde encontramos constantemente alusiones a diferentes tipos de mujeres, las de "casa" y aquellas que pertenecen a un estrato social bajo y que están en continuo riesgo de ser violentadas. A través de la voz de LA PONCIA en acto II hallamos no sólo la pista de estas mujeres libres, pertenecientes a otra clase social, pero sobre todo, el prejuicio de la mujer que baila:

LA PONCIA. De muy lejos. Vinieron de los montes. ¡Alegres! ¡Como árboles quemados! ¡Dando voces y arrojando piedras! Anoche llegó al pueblo una mujer vestida de lentejuelas y que bailaba con un acordeón, y quince de ellos la contrataron para llevársela al olivar. Yo los vi de lejos. El que la contrataba era un muchacho de ojos verdes, apretado como una gavilla de trigo. (1485)

En este diálogo vemos la descripción de "una mujer vestida con lentejuelas" que bien puede aludir a una prostituta, debido a que la vestimenta es también un indicador social en su dimensión íntima y pública, es un símbolo transcendental. La mujer vestida con lentejuelas y ornamentos brillantes era considerada elegante en determinados ambientes de la alta sociedad, pero cuando estos eran portados por una mujer sin rango, su significado cambiaba totalmente: "clothing was the material creator of social position and an important tool of social regulation [...] is a system of signs that reflected, indeed helped construct, the social order” (Olson 2012: 1). Así, esta mujer que de acuerdo con LA PONCIA se va con quince hombres, se describe, además, por la vestimenta de lentejuelas y por su actividad de bailar con un acordeón, poniendo otra vez de relieve la estigmatización del baile como una actividad 
impúdica y libertina en contraste con los valores de las mujeres de la casa de BERNARDA, celosas de su castidad y preocupadas hasta la obsesión por las habladurías.

Otro ejemplo del baile vinculado a significados sociales lo hallamos en Yerma, en el diálogo que sostiene la protagonista con LA VIEJA 1.a, donde saltan a la vista los contrastes. La primera que joven y fuerte sufre por estar "seca", y la segunda que vieja ha tenido "nueve hijos como nueve soles." (1287). Mientras YERMA es mujer de su casa y su marido, la VIEJA ha tenido dos maridos, amante del jolgorio, y sobre todo, una mujer que ha sido fértil. Cuando la VIEJA afirma que conoce al padre YERMA que conoció a su padre, lo describe e inmediatamente se describe ella y su temperamento contrastante:

VIEJA: ¡Ah! Enrique el Pastor. Lo conocí. Buena gente. Levantarse. Sudar, comer unos panes y morirse. Ni más juego, ni más nada. Los juegos para otros. Criaturas de silencio. Pude haberme casado con un tío tuyo. Pero ¡ca! Yo he sido una mujer de faldas en el aire, he ido flechada a la tajada del melón, a la fiesta, a la torta de azúcar. Muchas veces me he asomado de madrugada a la puerta creyendo oír música de bandurrias que iba, que venía, pero era el aire. (Ríe.) Te vas a reír de mí. He tenido dos maridos, catorce hijos, cinco murieron y, sin embargo, no estoy triste, y quisiera vivir mucho más. (1287)

La vitalidad y libertad de la VIEJA chocan con el carácter y las circunstancias de la protagonista, siempre custodiada por su marido y las dos hermanas de éste. Cuando la VIEJA dice "una mujer de faldas en el aire", podemos intuir que se refiere al baile, pero también a la emancipación sexual. Es ella le que pregunta a YERMA si desea a su marido como hombre, y de nueva cuenta, salta la alusión del baile y su implícita cercanía de los cuerpos como una demostración del deseo:

VIEJA 1.a: ¿No tiemblas cuando se acerca a ti? ¿No te da así como un sueño cuando acerca sus labios? Dime. 
YERMA: No. No lo he sentido nunca.

Vieja 1.a: ¿Nunca? ¿Ni cuando has bailado?

Yerma. (Recordando.) Quizá... Una vez... Víctor. (1289)

Este vínculo entre la fertilidad, baile y deseo quedarán claramente de manifiesto en el acto III, cuadro II, en la danza ritual de los ritos agrícolas en la que se ve una pareja enmascarada. El acto mismo que representa la unión sexual del hombre y mujer, estilizado y poetizado en la visión lorquiana, pero que conserva en el mundo de la obra, su sentido social original, del deseo descarnado y lujurioso: "MACHO: Siete veces gemía/ nueve se levantaba, /quince veces juntaron/ jazmines con naranjas" (1342). La dominación y violencia masculina sobre el cuerpo de la mujer como indicio de fertilidad, dan un paso más, aunque en el sentido poético:

HOMBRE 3.

¡Dale ya con el cuerno!

HOMBRE 2.

¡Con la rosa y la danza!

HOMBRE 1.

¡Ay, cómo se cimbrea la casada! (1344)

En esta cita observamos tres aspectos diversos de la dominación masculina: la violencia expresada con "el cuerno", la suavidad de "la rosa y la danza", y el cimbreo de la casada, es decir, su regocijo ante el acto sexual, que en el lenguaje poético de Lorca sublima el momento furioso del baile que, en sí mismo, deja bastante claro su significado, pues muchos bailes populares fueron condenados y prohibidos por su crudeza, el uso fogoso del pecho, caderas y piernas en movimientos circulares y evolventes que han sido considerados en los entornos populares como buenos para el vientre femenino y la fertilidad. Estos bailes son parecidos a 
los llamados "bailes animales" que pueden ser encontrados en los rituales las culturas primitivas: "during these magical rites, dancers pantomimed the movements of animals, believing by imitation they could harness, control, and animal's strength, agility, speed and cunning. Animal dances were used during initiation rites, fertility rites, courtship rituals, funerals rituals and hunt rituals" (Knowles 2009: 61). Lorca logra conjugar poéticamente la fuerte imagen de las danzas rituales con su estilización:

\author{
MACHO. \\ Que se queme la danza \\ Y el cuerpo reluciente \\ De la linda casada. \\ (Se van bailando con son de palmas y sonrisas. Cantan. ) \\ El cielo tiene jardines \\ Con rosales de alegría, \\ Entre rosal, \\ La rosa de maravilla. (1343)
}

Lorca plasma la fuerza de instinto sexual en esta escena, contrapuesto con las rígidas ataduras sociales que YERMA no se atreve a romper. La tragedia de la protagonista radica en que su instinto no es tan fuerte como su sentido del deber, incluso después del ofrecimiento para YERMA deje a su marido y se una al hijo de la VIEJA. Queda planteada la dualidad de la mujer una vez más en estas dos figuras, de liberación contra sumisión y que no deja de estar asociado por el autor como una cuestión de "sangre", pues cuando la VIEJA se refiere a la familia de YERMA “criaturas de silencio.” Por el otro lado, la familia de JUAN es considerada como fallida o dudosa en el rol de procreación: "VIEJA: La culpa es de tu marido [...] Ni su padre, ni su abuelo, ni su bisabuelo se portaron como hombres de casta" (1344). El hombre visto desde la perspectiva lorquiana también tiene un sentido crítico, el hombre con capacidad económica pero incapaz de satisfacer a la mujer. 
En este sentido, Bodas de sangre propone justamente lo opuesto a las anteriores protagonistas, pues la NOVIA al contrario que YERMA, sí se atreve a romper con su rol pasivo e indeciso. Sin embargo, el error de la NoviA es "obviar" la "casta" del Novio, hombre de bailarines, es decir, hombres de fuerza como lo señala la MADRE:

PADRE. (A la MADRE) Mira el baile que tienen formado. Bailes de allá de la orilla del mar [...] MADRE. Son los primos de mi marido. Duros como piedras para la danza.

PADRE. Me alegra de verlos. ¡Qué cambio para esta casa! (Se va). (1231)

Cuando la MADRE refiere que los hombres de su casa son "duros como piedras para la danza" sin duda deja de manifiesto la potencia física que poseen y el rol de hombres fuertes en su comunidad, qué más adelante se confirma en el diálogo entre el NoviO y la CRIADA, cuando ella recuerda al abuelo de éste. En el breve diálogo, ambos hacen referencia al baile, asociado a sus propios atributos femeninos y masculinos:

CRIADA. Aquello está hermoso

NOVIO. ¿Y tú no bailas?

CRIADA. No hay quien me saque.

(Pasan al fondo dos Muchachas; durante todo este acto, el fondo será un animado cruce de figuras.)

Novio. (Alegre.) Eso se llama no entender. Las viejas frescas como tú bailan mejor que las jóvenes.

CRIADA. Pero ¿vas a echarme requiebros, niño? ¿Qué familia la tuya! ¡Machos entre los machos! Siendo niña vi la boda de tu abuelo. ¡Qué figura! Parecía como si se casara un monte. (1233-34)

Si consideramos que, así como el baile se relaciona con los atributos femeninos de coquetería, conquista, atracción, incluso de salud y alegría que acompañan a los de fertilidad (y por lo cual se vuelve peligrosa), la danza masculina se percibe como una característica de 
poder, de fuerza y atletismo, especialmente en las culturas agrícolas, donde el hombre, en relación a la mujer, domina más que conquista. Así, el baile se vuelve un atributo de orgullo y dominio. Si tenemos en cuenta que Lorca seguramente se refería al flamenco, por la cercanía de tradición andaluza con la que él creció, las particularidades de masculinidad y feminidad son muy claros en este baile: "The male dancer emphasized the footwork, a symbol of strength and virility" (Pohren 2014: 60), mientras que los movimientos de las mujeres hacen hincapié en el movimiento de los brazos y el torso, además del movimiento de su vestido, símbolo de feminidad y pasión. Pero incluso si en la obra de Lorca no se hablara específicamente del flamenco, las danzas tradicionales de muchos pueblos guardan asombrosas similitudes en tanto a las implicaciones sexuales y sociales que expresan de manera no verbal. Como afirma Alberto Dallal, sobre las danzas emanadas del folclore de un pueblo, éstas tienden a repetir ciertos aspectos de conducta humana y costumbres vinculadas el campo como momentos para la danza: “[...] las temporadas de siembras y de cosecha, los aspectos de iniciación comunal, los ritos o costumbres de noviazgo, petición de matrimonio, pacto amoroso. También resultan semejantes ciertas situaciones de acoso o requerimiento amoroso sexual, así como la sanción o reconocimiento de casas, tierras de labranza, paternidad, urgimiento de autoridad” (Dallal 2007: 53). Así, las significaciones sobre masculinidad y feminidad a través de la danza cobran una importancia para el entendimiento del entorno de los personajes lorquianos, aunque estas no sean abundantes, dicen más de lo que aparentan. Por ejemplo, en El público, Lorca deja velado otro tipo de masculinidad que danza, totalmente distinta al que observamos en Bodas. En la Loa al PASTOR BOBO que abre la obra, aparece descrito como que "toca un aristón y danza con ritmo lento" (Lorca, El Público, 100) establece un mensaje distinto de masculinidad con su cuerpo, una danza "a 
ritmo lento", que se aleja de lo que mencionábamos anteriormente de los atributos de la hombría y bravura. Más adelante, cuando aparecen la FIGURA dE PÁMPANOS y LA FigURA DE CASCABEL, Lorca va más allá y presenta dos personajes que establecen una relación a través de la danza. Menciona Javier Huerta Calvo:

En un ámbito que nos traslada a otro tiempo, la Roma antigua, sólo que en figura de ruina, asistimos al segundo ritual homoerótico del drama: la danza y la lucha que van a sostener dos personajes de filiación pagana, la Figura de Pámpanos y la Figura de Cascabeles. La danza se resuelve verbalmente en una serie de preposiciones condicionales y de respuestas, a través de las cuales las dos figuras aparecen contender por su mayor o menor masculinidad en la relación amorosa. (Huerta 2006: 36-37)

En este diálogo, donde la FIGURA DE CASCABEL "danza en el centro de la escena" ilustran un encuentro amoroso homo-erótico donde hay una pugna por el juego de roles, aunque la figura que danza posee ya una feminización no cede al sometimiento cuando la FIGURA DE PÁMPANOS le dice "Yo me convertiría en cuchillo" (Lorca 2006: 126), en alusión fálica, pero que también se ha interpretado como símbolo de dominio, violencia y muerte, como señala Huerta Calvo. La FIGURA DE CASCABELES, “dejando de danzar” responde “[...] Si yo me convirtiera en pez luna, tú te convertirías en ola de mar o en alga, y si quieres algo muy lejano, porque no desees besarme, tú te convertirás en luna llena, ¡pero en cuchillo! Te gozas en interrumpir mi danza, y danzando es la única manera que tengo de amarte" (125). De nueva cuenta vemos que la danza está inmersa en otros significados estrechamente unidos a la sexualidad y el deseo. Mientras el "cuchillo" puede simbolizar una materialización carnal y así una destrucción del deseo, la danza expresa la continuación de ese platonismo, que es la única manera de amar de la FiguRA DE CASCABELES, es decir, a través del cuerpo que se muestra pero que no se entrega. 
En resumen, es llamativo ver cómo en las obras de Lorca hay un vínculo con lo natural, y también con el instinto humano: el choque entre el deseo de sus personajes con las normas impuestas por la sociedad en la que se desenvuelven, la cual es el catalizador de sus conflictos. Las referencias al baile en Lorca tienen un significado más profundo por su relación social, que dice mucho sin decirlo directamente. Debajo del discurso de las palabras subyace un lenguaje más elocuente que es el del cuerpo, un tipo de comunicación que es esencialmente dramática, narrativa y social. Es inevitable observar de nueva cuenta cómo el cuerpo se vincula a ideas sociales y morales, pues como indica Judith Butler, los cuerpos hablan sobre el mundo que está más allá de ellos mismos y esto supera su propia materialidad, determinan al sujeto a través de ideas de género, mismas que van a establecer relaciones de poder y normatividad (Butler 1993: 11,14). El deseo y la pulsión sexual, tan presente en las obras de Lorca, va a ser demarcado por las concepciones de moralidad que establece la cultura y que van configurando su universo.

Mary Beard en su libro Mujeres y poder, observa la historia del silencio femenino en los ámbitos públicos a lo largo de la historia de occidente, una situación que ha permeado a lo largo de las épocas, fijando y acrecentando prejuicios hacia la mujer. Esta tradición de acallar la voz femenina conduce a pensar en todos aquellos otros lenguajes por los cuales la mujer ha sido capaz de expresarse, uno de los cuales es sin duda el de la danza, del que Lorca fue un claro receptor. Si bien en sus obras le interesa observar el conflicto de la mujer oprimida por sus circunstancias, deja latente otro tipo de mujer dibujada en el fondo: el de la criada, la vieja, las muchachas, aquellas mujeres en la periferia más perspicaces y audaces, aquellas que bailan y cantan, pero que también están excluidas y "mal vistas", una franja 
impuesta entre unas y otras, una separación de clases, de conductas, de posturas morales, pero que, de alguna manera, hace a estas mujeres, en el fondo, parecer más felices.

\section{Referencias bibliográficas}

Beard, Mary. 2018. Mujeres y poder. Un manifiesto. Barcelona: Planeta de Libros.

Butler, Judith. 1993. Cuerpos que importan. Sobre los límites materiales y discursivos del sexo. México. D.F.: Paidós.

Dallal, Alberto. 2007. Los elementos de la danza. México DF.: Universidad Nacional Autónoma de México.

García Lorca, Federico. 1971. Obras completas. Madrid: Aguilar. . 2006. El Público. Madrid: Espasa Calpe.

Homans, Jennifer. 2010. Apolo's Angels. New York: Random House.

Huerta Calvo, Javier. 2006. “Introducción”. El Público. Madrid: Espasa Calpe.

Knowles, Mark. 2009. The Wicked Waltz and Other Scandalous Dances: Outrage at Couple Dancing in the 19th and Early 20th Centuries. North Carolina: McFarland \& Company.

Makarova, Natalia. 1987. Ballerina. Body and soul. BBC. https://www.youtube.com/watch?v=nPC1qQKF0SA\&t=1344s [30 de septiembre de 2017].

Murga de Castro, Idoia. 2009. Escenografía de la danza en la Edad de Plata (1916-1936). Madrid: Consejo Superior de Investigaciones Científicas.

Noverre, Georges. 1975. Letters on dancing and ballets. Brooklyn. N.Y.: Dance Horizons.

Pohren, D.E. 2014. The Art of flamenco. Delawere: Createspace Independent Pub.

Olson, Kelly. 2008. Dress and the Roman Woman: Self-Presentation and Society. New York: Routledge. Taylor \& Francis Group.

Wagner, Ann.1997. Adversaries of dance. From the Puritans to the present. Illinois: University of Illinois Press/Urbana and Chicago. 